\title{
Inhibition of interleukin $1 \beta$ induced rat and human cartilage degradation in vitro by the metalloproteinase inhibitor U27391
}

\author{
M P Seed, S Ismaiel, C Y Cheung, T A Thomson, C R Gardner, R M Atkins, C J Elson
}

Roussel Laboratories Ltd, Kingfisher Drive, Covingham, Swindon, Wiltshire SN3 5BZ, United Kingdom M P Seed C Y Cheung T A Thomson C R Gardner

Department of Pathology and Microbiology, School of

Medical Sciences,

Bristol University,

Bristol BS8 1TD,

United Kingdom

$S$ Ismaiel

C J Elson

Department of Orthopaedics,

Bristol Royal Infirmary, Bristol BS2 8HW, United Kingdom R M Atkins

Correspondence to: Dr M P Seed,

Departments of

Experimental Pathology

and Rheumatology,

St Bartholomew's

Hospital Medical College,

Charterhouse Square,

London EC1M 6BO

United Kingdom.

Accepted for publication 20 August 1992

\begin{abstract}
Interleukin 1 induced proteoglycan loss from cartilage in vitro was prevented by a biochemical inhibitor of metalloproteinase activity. The inhibitor also partially relieved the inhibition of proteoglycan synthesis caused by interleukin 1 . The loss of glycosaminoglycan by rat and human femoral head cartilage in response to human recombinant interleukin $1 \beta$ (rhIL-1 $\beta$ ) was established, and the modulation of this loss by the metalloproteinase inhibitor U27391 was investigated. Rat femoral head cartilage consistently lost glycosaminoglycan in response to rhIL-1 $\beta$ whereas only a proportion $(30 \%)$ of normal human femoral head cartilage did so. Concentrations of $10-100 \mu \mathrm{mol} / 1 \mathrm{U} 27391$ inhibited the action of rhIL-1 $\beta$ on rat femoral head cartilage, reversing both the loss of glycosaminoglycan and the inhibition of glycosaminoglycan synthesis. U27391 also prevented the reduction in glycosaminoglycan content of those human femoral head cartilage explants responsive to rhIL-1 $\beta$. Metalloproteinase inhibition therefore prevents rhIL-1 $\beta$ induced glycosaminoglycan loss by rat and human femoral head cartilage, suggesting that inhibitors of such enzymes may prove to be of therapeutic benefit in erosive diseases in humans.
\end{abstract}

(Ann Rheum Dis 1993; 52: 37-43)

Osteoarthritis (OA) and rheumatoid arthritis (RA) cause substantial articular cartilage erosion and loss of matrix in the affected joints of patients, which can lead to a severe compromise of function. Fundamental experiments by Fell and $\mathrm{Jubb}^{1}$ identified the importance of synovium derived catabolic factor(s) which were capable of inducing cartilage damage in vitro, a constituent of which was later identified as interleukin 1 (IL-1). ${ }^{2}$ Interleukin 1 has since been implicated in the cartilage damage seen with OA and RA. It is synthesised by the diseased synovium in $\mathrm{OA}$ and $\mathrm{RA}^{34}$ and can be found in synovial fluids from patients with OA and RA. ${ }^{47}$ It is well established that recombinant human IL-1 (rhIL-1) can induce matrix loss, usually assessed as the loss of sulphated glycosaminoglycans, from the cartilage of several animal species in vitro $^{2}{ }^{8-11}$ and in vivo. ${ }^{12-14}$ Initial case reports using IL-1 harvested from cells illustrated that it was possible to induce degradation of human cartilage..$^{15} 16$ It was not until later, however, that rhIL-1 $\beta$ was shown unambiguously to degrade normal articular cartilage and then only after prolonged (14 days) incubation with specimens from certain subjects. ${ }^{17}$

There is evidence that cartilage matrix degradation stimulated by IL-1 involves the action of metalloproteinases. For example, articular cartilage from pigs which is incubated with IL-1 releases proteoglycan fragments consistent with the action of one or more enzymes of this type. ${ }^{8}{ }^{18}$ Interleukin 1 induces the release of metalloproteinases from human cartilage explants ${ }^{15} 16$ as well as from chondrocytes from various species, ${ }^{19-23}$ and these enzymes are capable of degrading cartilage matrix components. ${ }^{15} 16212224$ Campbell et $a l^{25}$ have since shown that proteoglycan fragments released by IL-1 stimulated human cartilage in situ have similar qualitative characteristics to those released by the isolated metalloproteinase in vitro.

Although it can be shown that classical metalloproteinase inhibitors such as EDTA, 1,10-phenanthroline, and $\alpha_{2}$ macroglobulin will reduce the activity of this class of IL-1 inducible enzyme in isolation, 20222627 direct evidence that the inhibition of these enzymes in situ will prevent the destructive action of IL-1 is sparse, if only due to non-specific actions of the agents on the chondrocyte, ${ }^{28-30}$ or size exclusion from the cartilage. Several series of substrate inhibitors have been developed for an IL-1 inducible rabbit chondrocyte metalloproteinase, namely thiol, carboxyalkyl and hydroxamic acid peptides, ${ }^{91}$ with the aim of developing agents which will alleviate cartilage destruction in arthritic disease. ${ }^{32}$ Of these, the hydroxamic acid peptides are the most potent and two have been reported to inhibit IL-1 induced proteoglycan loss from rabbit articular cartilage in vitro. ${ }^{9}$ Chemicals of this series are effective against the rabbit chondrocyte metalloproteinases collagenase and proteoglycanase which are induced by IL- $1 .^{32}$ Here we describe experiments which assessed the ability of a hydroxamic acid peptide, U27391, to modulate IL-1 induced proteoglycan loss and synthesis inhibition by rat femoral head articular cartilage and compared this with the same tissue obtained from humans.

\section{Materials and methods}

RAT FEMORAL HEAD CARTILAGE

Rat femoral head cartilage was incubated as described previously. ${ }^{11}$ Cartilage from 110 $120 \mathrm{~g}$ male CFHB (Wistar strain, Interfauna) rats was dissected aseptically and washed serially. Optimum conditions were assessed by comparing RPMI 1640 containing $2 \cdot 0 \mathrm{~g} / \mathrm{l}$ glucose, $1 \mathrm{mM}$ sodium pyruvate, $1 \mathrm{mM}$ 
glutamine, $100 \mathrm{U} / \mathrm{ml}$ penicillin, $100 \mu \mathrm{g} / \mathrm{ml}$ streptomycin, and $5 \%$ fetal calf serum, with Dulbecco's modified Eagle's medium (DMEM) containing $25 \mathrm{mM}$ HEPES, 2.0 or $4.5 \mathrm{~g} / \mathrm{l}$ glucose with $1 \mathrm{mM}$ sodium pyruvate, $1 \mathrm{mM}$ glutamine, $100 \mathrm{U} / \mathrm{ml}$ penicillin, $100 \mu \mathrm{g} / \mathrm{ml}$ streptomycin, and $5 \%$ fetal calf serum. Cartilage explants were preincubated for 48 hours at $37^{\circ} \mathrm{C}$ in a humidified atmosphere of $5 \% \mathrm{CO}_{2} / 95 \%$ air in $2 \mathrm{ml}$ medium on a rocker. The cartilages were then placed in fresh medium containing the drug vehicle and either U27391 (1-100 $\mu \mathrm{mol} / \mathrm{l})$ alone, rhIL-1 $\beta$ (100 $\mathrm{ng} / \mathrm{ml})$ alone, or $\mathrm{rhIL}-1 \beta$ plus U27391 (1-100 $\mu \mathrm{mol} / \mathrm{l})$ for a further five days. Cartilage proteoglycan synthesis was assessed by the addition of sodium $\left[{ }^{35} \mathrm{~S}\right]$ sulphate $(0.46 \mathrm{kBq} / \mathrm{ml}) 16$ hours before termination. Control cartilages were killed by freezing $\left(-20^{\circ} \mathrm{C}\right)$ and thawing $\left(54^{\circ} \mathrm{C}\right.$ for 30 minutes $)$ and incubated with sodium $\left[{ }^{35} \mathrm{~S}\right]$ sulphate as for the living cartilage.

At termination the cartilages were removed and vortexed three times in $10 \mathrm{mM} \mathrm{MgSO}_{4}$ to remove inorganic $\left[{ }^{35} \mathrm{~S}\right]$ sulphate. The cartilages were then weighed, and placed in $2 \mathrm{ml}$ papain digestion buffer $(20 \mathrm{mM}$ disodium hydrogen orthophosphate, $1 \mathrm{mM}$ EDTA, $2 \mathrm{mM}$ dithiothreitol, and $0.25 \mathrm{mg} / \mathrm{ml}$ papain) and digested for three hours at $65^{\circ} \mathrm{C} .{ }^{33}$ The media were diluted $1: 2$ in papain digestion buffer and digested as described earlier.

The degree of $\left[{ }^{35} \mathrm{~S}\right]$ sulphate incorporation into glycosaminoglycans was assessed by the method of Jubb and Fell. ${ }^{34}$ A $50 \mu$ l volume of $10 \%$ cetylpyridinium chloride was added to 0.5 $\mathrm{ml}$ papain digest and incubated at $37^{\circ} \mathrm{C}$ for one hour. The samples were centrifuged at $13000 \mathrm{~g}$ for 10 minutes and the supernatant aspirated. The glycosaminoglycan pellet was dissolved in $300 \mu \mathrm{l}$ formic acid at $70^{\circ} \mathrm{C}$ for 10 minutes and added to $4 \mathrm{ml}$ Optifluor with $0.5 \mathrm{ml}$ papain buffer. The supernatants were also added, with $300 \mu \mathrm{l}$ formic acid to ensure comparable quenching, to $4.0 \mathrm{ml}$ Optifluor for liquid scintillation counting. The cartilage digests were then assessed for $\left[{ }^{35} S\right]$ sulphate incorporation by liquid scintillation counting $(0.5 \mathrm{ml}$ digest : $5 \mathrm{ml}$ Optifluor). Once the degree of $\left[{ }^{35}\right.$ S]sulphate incorporation into the glycosaminoglycan fraction had been determined, glycosaminoglycan synthesis in all further experiments was assessed by the content of $\left[{ }^{35} \mathrm{~S}\right]$ sulphate in the cartilage digest.

The cartilage and medium were assessed for sulphated glycosaminoglycan content, assayed as chondroitin sulphate equivalents using the dimethyl methylene blue binding method $^{33}$ modified for use on a microplate reader (Multiscan MCC 340 MkII), and analysed using Titertek software (Flow Laboratories).

The loss of glycosaminoglycan from the cartilages was expressed as micrograms chondroitin sulphate equivalents released per milligram wet weight of cartilage ( $\mu$ g glycosaminoglycan $/ \mathrm{mg}$ ). Data were expressed as mean (SEM) and analysed by ANOVA with comparison of means (RS-1, BBN software). were obtained from the femoral heads of patients undergoing hemiarthroplasty following osteoporotic subcapital fracture of the femoral neck. Biopsy samples $(3 \times 3 \mathrm{~mm})$ were taken from the human femoral head cartilage slices using a biopsy punch and each was cut in half. The two pieces were cultured and incubated as described in detail elsewhere. ${ }^{17}$ In brief, one half (control biopsy) was cultured in $2 \mathrm{ml}$ RPMI 1640 containing $2 \mathrm{mM}$ L-glutamine, $100 \mathrm{U} / \mathrm{ml}$ penicillin and $100 \mu \mathrm{g} / \mathrm{ml}$ streptomycin, $25 \mathrm{mM}$ HEPES and $5 \%$ normal human $\mathrm{AB}$ serum. The other half (treated biopsy) was cultured in $2 \mathrm{ml}$ RPMI 1640 containing either $10 \mathrm{ng} / \mathrm{ml}$ rhIL-1 $\beta$ alone or $10 \mathrm{ng} / \mathrm{ml}$ rhIL-1 $\beta$ plus U27391 (1-100 $\mu \mathrm{mol} / \mathrm{l})$. Each treatment was tested on 10 biopsy samples.

The cultures were incubated for 14 days at $37^{\circ} \mathrm{C}$ in a humidified atmosphere of $\mathrm{CO}_{2}$ /air, and the media changed every two days. At the end of the culture period, the biopsy samples were blotted dry, weighed, and assayed for glycosaminoglycan using the technique described for rat femoral head cartilage. The glycosaminoglycan content of each half biopsy sample was expressed as micrograms glycosaminoglycan per milligram cartilage. The cartilage glycosaminoglycan content of each treated biopsy sample was compared with its paired untreated control using the Wilcoxon test. Owing to the zonal variation in the proteoglycan content of the human femoral head cartilage, the results were expressed as the percentage reduction in proteoglycan content induced by rhIL-1 $\beta$, calculated as follows.

$\%$ reduction in cartilage glycosaminoglycan $=100-(($ glycosaminoglycan in treated biopsy/glycosaminoglycan in control biopsy) $\times 100$ )

\section{MATERIALS}

Recombinant human IL- $1 \beta$ produced by the expression of the carboxyl terminal 153 amino acids of the 269 amino acid precursor in Escherichia coli and purified to homogeneity as assessed by sodium dodecylsulphate polyacrylamide gel electrophoresis was obtained from Roussel UCLAF, Paris. Its activity in the lymphocyte activation factor assay was $100 \mathrm{pg}$ per unit and the endotoxin content was less than $1 \mathrm{ng} / \mathrm{mg}$ as determined by the Limulus assay. U27391 ( $R, S)-N$-[2-[2-(hydroxyamino)2-oxoethyl]-4-methyl-1-1 oxopentyl]-L-leucyl-L phenyl alaninamide) was kindly supplied by Stuart Pharmaceuticals (ICI, Americas). Dulbecco's modified Eagle's medium, penicillin, streptomycin, sodium pyruvate, glutamine, and<smiles>CC(C)CC(CC(=O)N(C)O)C(=O)NC(CC(C)C)C(=O)NC(Cc1ccccc1)C(N)=O</smiles>

Figure 1 Structure of U27391 ((R,S)-N-[2-[2(hydroxyamino)-2-oxoethyl]-4-methyl-1-1 oxyopentyl]-Ileucyl-L-phenyl alaninamide). 
fetal calf serum were supplied by Gibco (Paisley, United Kingdom), and sodium [ ${ }^{35}$ S] sulphate by Amersham International. All other chemicals were supplied by Sigma (UK).

\section{Results}

INCORPORATION OF $\left[{ }^{35}\right.$ s]SULPHATE INTO RAT FEMORAL HEAD CARTILAGE GLYCOSAMINOGLYCAN Twenty samples of rat femoral head cartilage incubated in DMEM supplemented with $4.5 \mathrm{~g} / 1$ glucose for four days incorporated 3324.0 (379.9) cpm $\left[{ }^{35}\right.$ S]sulphate. A total of $97 \cdot 2$ $(0.6) \%$ of the $\left[{ }^{35} \mathrm{~S}\right]$ sulphate was incorporated into precipitable glycosaminoglycan from living rat femoral head cartilage, indicating that most of the label was incorporated into glycosaminoglycan. Dead cartilage, after washing with 10 $\mathrm{mM} \mathrm{Mg} \mathrm{Mg}_{4}$, contained $65.0(12.0) \mathrm{cpm}$. For all subsequent experiments the $\left[{ }^{35} S\right]$ sulphate content of the rat femoral head cartilage papain digest was taken as an indication of glycosaminoglycan synthesis.

\section{INCUBATION CONDITIONS FOR RAT FEMORAL HEAD CARTILAGE}

A comparison was made between basal and rhIL-1 $\beta$ (100 ng/ml) stimulated rat femoral head cartilage cultured in either RPMI 1640 $(2.0 \mathrm{~g} / 1$ glucose $)$ or DMEM $(2.0$ or $4.5 \mathrm{~g} / 1$ glucose) to optimise the conditions required for $\left[{ }^{35}\right.$ S]sulphate incorporation and glycosaminoglycan loss. Table 1 shows that $\left[{ }^{35}\right.$ S $]$ sulphate incorporation by unstimulated rat femoral head cartilage was highest when the rat femoral head cartilage was incubated in DMEM with $4.5 \mathrm{~g} / \mathrm{l}$ glucose, especially when compared with $2.0 \mathrm{~g} / \mathrm{l}$ glucose DMEM. Spontaneous glycosaminoglycan loss into the medium was also considerably higher from the latter samples. Incubation in RPMI 1640 gave a comparable spontaneous loss of glycosaminoglycan to $4.5 \mathrm{~g} / \mathrm{l}$ glucose DMEM, though slightly and statistically significantly lower. Incubation with $100 \mathrm{ng} / \mathrm{ml} \mathrm{rhIL}-1 \beta$ showed that stimulated glycosaminoglycan release was highest (a 123\% increase; $p<0.001$ ) in the presence of $4.5 \mathrm{~g} / 1$ glucose DMEM, whereas that in the presence of RPMI 1640 was less significant $(33.7 \% ; p<0.05)$. This, coupled with the high incorporation of $\left[{ }^{35} \mathrm{~S}\right]$ sulphate in the $4.5 \mathrm{~g} / 1 \mathrm{DMEM}$, led to the choice of this medium for subsequent experiments.

RECOMBINANT HUMAN INTERLEUKIN $1 \beta$ INDUCED CARTILAGE DEGRADATION BY RAT FEMORAL HEAD CARTILAGE AND HUMAN FEMORAL HEAD

\section{CARTILAGE}

Recombinant human interleukin $1 \beta$ significantly increased glycosaminoglycan loss from rat

Influence of different culture media and glucose concentration on glycosaminoglycan loss and ${ }^{35} S /$ sulphate incorporation by rat femoral head cartilage after five days incubation in vitro. Data are expressed as mean (SEM)

\begin{tabular}{|c|c|c|c|c|}
\hline & \multicolumn{2}{|c|}{ Glycosaminoglycan loss ( $\mu \mathrm{g} / \mathrm{mg})$} & \multicolumn{2}{|c|}{$I^{35} S /$ sulphate $(\mathrm{cpm})$} \\
\hline & Basal & $100 \mathrm{ng} / \mathrm{ml} \mathrm{rhIL}-1 \beta$ & Basal & $100 \mathrm{ng} / \mathrm{ml} \mathrm{rhIL}-\mathrm{l} \beta$ \\
\hline $\begin{array}{l}\text { RPMI } 1640(2 \cdot 0 \text { g/l glucose }) \\
\text { DMEM }(2 \cdot 0 \text { g/l glucose }) \\
\text { DMEM }(4 \cdot 5 \text { g/l glucose })\end{array}$ & $\begin{array}{l}3 \cdot 18(0 \cdot 19)^{*} \\
5 \cdot 53(0 \cdot 32)^{* * *} \\
3.87(0 \cdot 13)\end{array}$ & $\begin{array}{l}4 \cdot 25(0 \cdot 14)^{* * *} \\
8 \cdot 10(0 \cdot 45) \\
8 \cdot 63(0 \cdot 49)\end{array}$ & $\begin{array}{l}2407(170)^{*} \\
740(94)^{* *} \\
3097(275)\end{array}$ & $\begin{array}{l}648(88)^{* * *} \\
273(45)^{* * *} \\
1287(126)\end{array}$ \\
\hline
\end{tabular}

DMEM=Dulbecco's modified Eagle's medium; rhIL- $1 \beta=$ recombinant human interleukin $1 \beta$.

${ }^{*} \mathrm{p}<0.05 ;{ }^{* *} \mathrm{p}<0 \cdot 01 ;{ }^{* * *} \mathrm{p}<0.001(\mathrm{n}=10)$ when compared with $4.5 \mathrm{~g} / \mathrm{l}$ glucose DMEM.
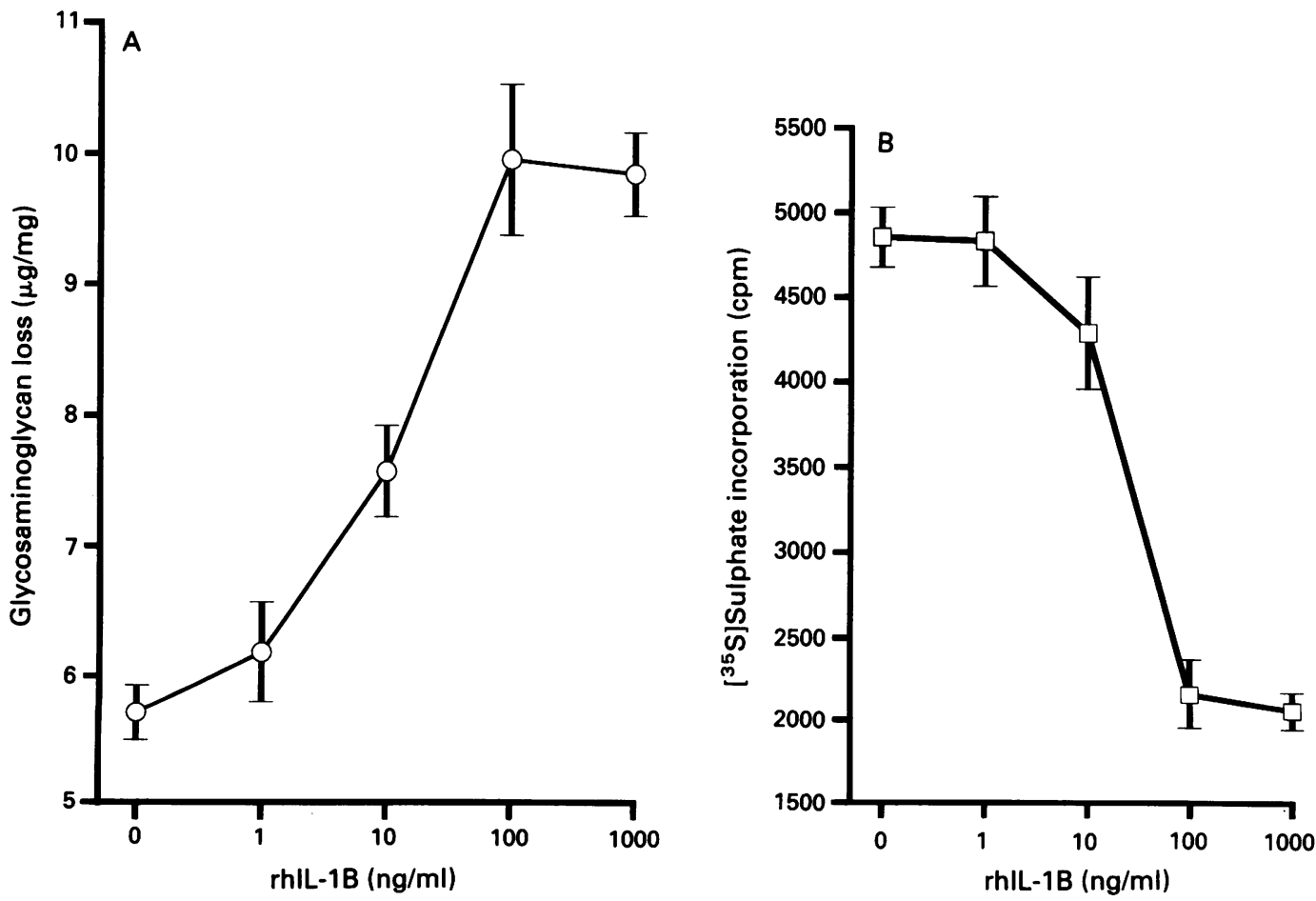

Figure 2 Induction of $(A)$ glycosaminoglycan loss ( $\mu g$ glycosaminoglycan/mg cartilage) and $(B)$ inhibition of $~^{35} S$ sulphate uptake (cpm per cartilage) by rat femoral head cartilage explants cultured with recombinant human interleukin $1 \beta($ rhIL-1 $\beta$ ) (mean $(S E M) ; n=10)$. Cartilages killed by freeze thawing contained $76 \cdot 5(8 \cdot 5) \mathrm{cpm}\left[{ }^{35} S\right.$ sulphate. 
femoral head cartilage into the medium from $5.71(0.22) \mu \mathrm{g} / \mathrm{mg}$ to a maximum of $9.91(0.58)$ $\mu \mathrm{g} / \mathrm{mg} \quad(\mathrm{n}=10 ; \mathrm{p}<0.001)$ at $100 \mathrm{ng} / \mathrm{ml}\left(E_{50}\right.$ $13 \cdot 1(2 \cdot 2) \mathrm{ng} / \mathrm{ml} ; \mathrm{n}=6)$ and concomitantly inhibited ${ }^{35}[S]$ sulphate incorporation by cartilage from $4855 \cdot 8(178 \cdot 8)$ to $2170 \cdot 3(210 \cdot 4)$ $\operatorname{cpm}(\mathrm{n}=10 ; \mathrm{p}<0.001)$ at $100 \mathrm{ng} / \mathrm{ml}\left(\mathrm{EC}_{50} 12.0\right.$ $(1 \cdot 6) \mathrm{ng} / \mathrm{ml} ; \mathrm{n}=6)$. There was no evidence of a preferential sensitivity of either glycosaminoglycan loss or ${ }^{35}[\mathrm{~S}]$ sulphate uptake to the action of rhIL-1 $\beta$ (fig 2) at five days of incubation. As $100 \mathrm{ng} / \mathrm{ml}$ rhIL-1 $\beta$ gave the greatest effect, this concentration was used when assessing the actions of U27391.

Recombinant human interleukin $1 \beta$ at 10 $\mathrm{ng} / \mathrm{ml}$ also stimulated human femoral head cartilage explants to lose glycosaminoglycan over 14 days. The reduction, compared with explants cultured with medium alone, was $18.6(2.6) \% \quad(\mathrm{n}=10 ; \quad \mathrm{p}<0.005), \quad 11.0(2.5) \%$ $(\mathrm{n}=10 ; \mathrm{p}<0.003)$, and $21 \cdot 0(3 \cdot 1) \% \quad(\mathrm{n}=10$; $\mathrm{p}<0.001)$ for cartilage from three subjects. In contrast, specimens from six other subjects showed no significant reduction in glycosaminoglycan content ranging from 1 to $8 \%$ loss $(\mathrm{n}=10)$. As $10 \mathrm{ng} / \mathrm{ml}$ rhIL-1 $\beta$ gave an appreciable loss of glycosaminoglycan from human femoral head cartilage, this concentration was used when assessing the action of U27391.

MODULATION OF RAT FEMORAL HEAD CARTILAGE GLYCOSAMINOGLYCAN LOSS AND SYNTHESIS BY U27391

The action of U27391 on the basal unstimulated release of glycosaminoglycan into the incubation medium was investigated. Figure 3 illustrates that at concentrations of $30 \mu \mathrm{mol} / \mathrm{l}$ and above, U27391 inhibited resting glycosaminoglycan release from $4 \cdot 28(0 \cdot 10)$ to $2 \cdot 90(0 \cdot 13) \mu \mathrm{g} / \mathrm{mg}$ at
$30 \mu \mathrm{mol} / \mathrm{l}(\mathrm{p}<0.01 ; \mathrm{n}=10)$ and $3.04(0 \cdot 17) \mu \mathrm{g} / \mathrm{mg}$ at $100 \mu \mathrm{mol} / 1(\mathrm{p}<0.05 ; \mathrm{n}=10)$. U27391 had no consistent action on $\left[{ }^{35} \mathrm{~S}\right]$ sulphate incorporation except for a statistically significant reduction in $\left[{ }^{35}\right.$ S $]$ sulphate incorporation at $1 \mu \mathrm{mol} / \mathrm{l}(\mathrm{p}<0.01$; $\mathrm{n}=10$ ).

\section{MODULATION OF RECOMBINANT HUMAN} INTERLEUKIN $1 \beta$ INDUCED RAT FEMORAL HEAD CARTILAGE GLYCOSAMINOGLYCAN LOSS AND SYNTHESIS BY U27391

Co-incubation of rat femoral head cartilage with U27391 resulted in a highly significant reduction in rhIL-1 $\beta$ stimulated glycosaminoglycan release from $9 \cdot 7(0.59)$ to $5 \cdot 24(0.42) \mu \mathrm{g} / \mathrm{mg}$ $(\mathrm{n}=10 ; \mathrm{p}<0.001$ at $10 \mu \mathrm{mol} / \mathrm{l}$, see fig $4 \mathrm{~A})$, and also reduced glycosaminoglycan loss to below basal levels at the highest concentration from $4 \cdot 28(0 \cdot 10)$ to $3 \cdot 48(0 \cdot 12) \mu \mathrm{g} / \mathrm{mg}(100 \mu \mathrm{mol} / \mathrm{l}$; $\mathrm{p}<0.05 ; \mathrm{n}=10)$. The rhIL-1 $\beta$ induced suppression of glycosaminoglycan synthesis remained unaffected by U27391 at $10 \mu \mathrm{mol} / \mathrm{l}$ (basal $6070 \cdot 2(188 \cdot 8) ; 100 \mathrm{ng} / \mathrm{ml}$ rhIL-1 $\beta 2873 \cdot 8(338 \cdot 3)$; $10 \mu \mathrm{mol} / 1 \mathrm{U} 273912807 \cdot 8(213 \cdot 5) \mathrm{cpm})$ but was significantly reversed at $100 \mu \mathrm{mol} / \mathrm{l}$ to 4460 $(286.2) \mathrm{cpm}(\mathrm{n}=10 ; \mathrm{p}<0.01$; see fig $4 \mathrm{~B})$. As with the unstimulated cartilage, U27391 at $1 \mu \mathrm{mol} / \mathrm{l}$ again significantly reduced $\left[{ }^{35} \mathrm{~S}\right]$ sulphate incorporation from $2873 \cdot 8(338 \cdot 8)$ to $1535 \cdot 7$ $(317 \cdot 5) \mathrm{cpm}(\mathrm{p}<0.01 ; \mathrm{n}=10)$.

MODULATION OF GLYCOSAMINOGLYCAN LOSS FROM HUMAN FEMORAL HEAD CARTILAGE BY U27391

Only results from cartilage explants which were responsive to degradative stimuli by rhIL-1 $\beta$ are given. For one such cartilage sample, the explants were incubated with $10-100 \mu \mathrm{mol} / \mathrm{l}$
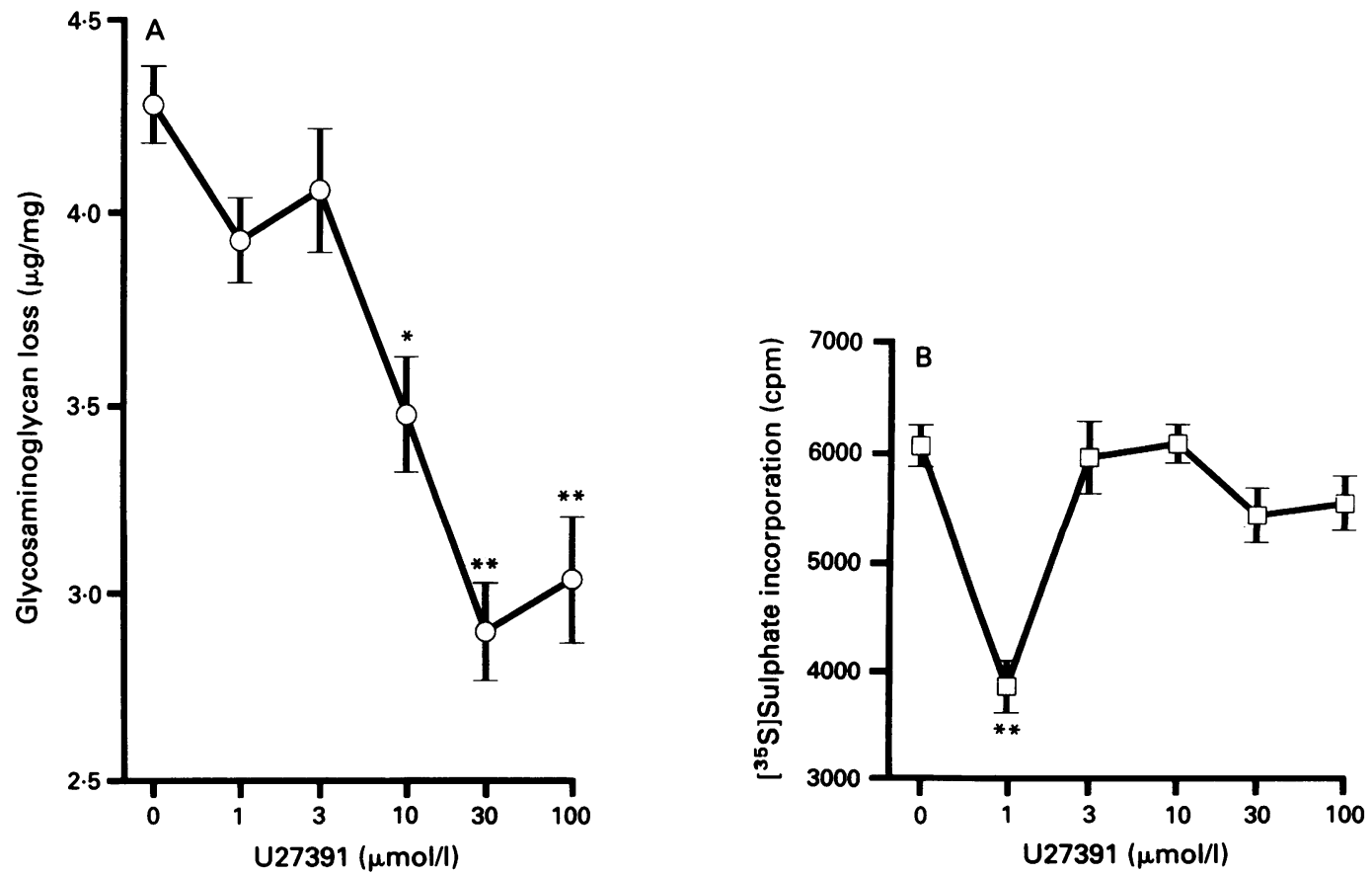

Figure 3 Effect of U27391 (1-100 umolll) on the basal (A) glycosaminoglycan release and $(B) \int^{35}$ Ssulphate incorporation by rat femoral head cartilage in culture (mean $(S E M)) .{ }^{* *} p<0 \cdot 01 ;{ }^{*} p<0 \cdot 05 ; n=10$. Cartilages killed by freeze thawing contained $67 \cdot 7(8 \cdot 7) \mathrm{cpm}\left[^{55}\right.$ Ssulphate. 

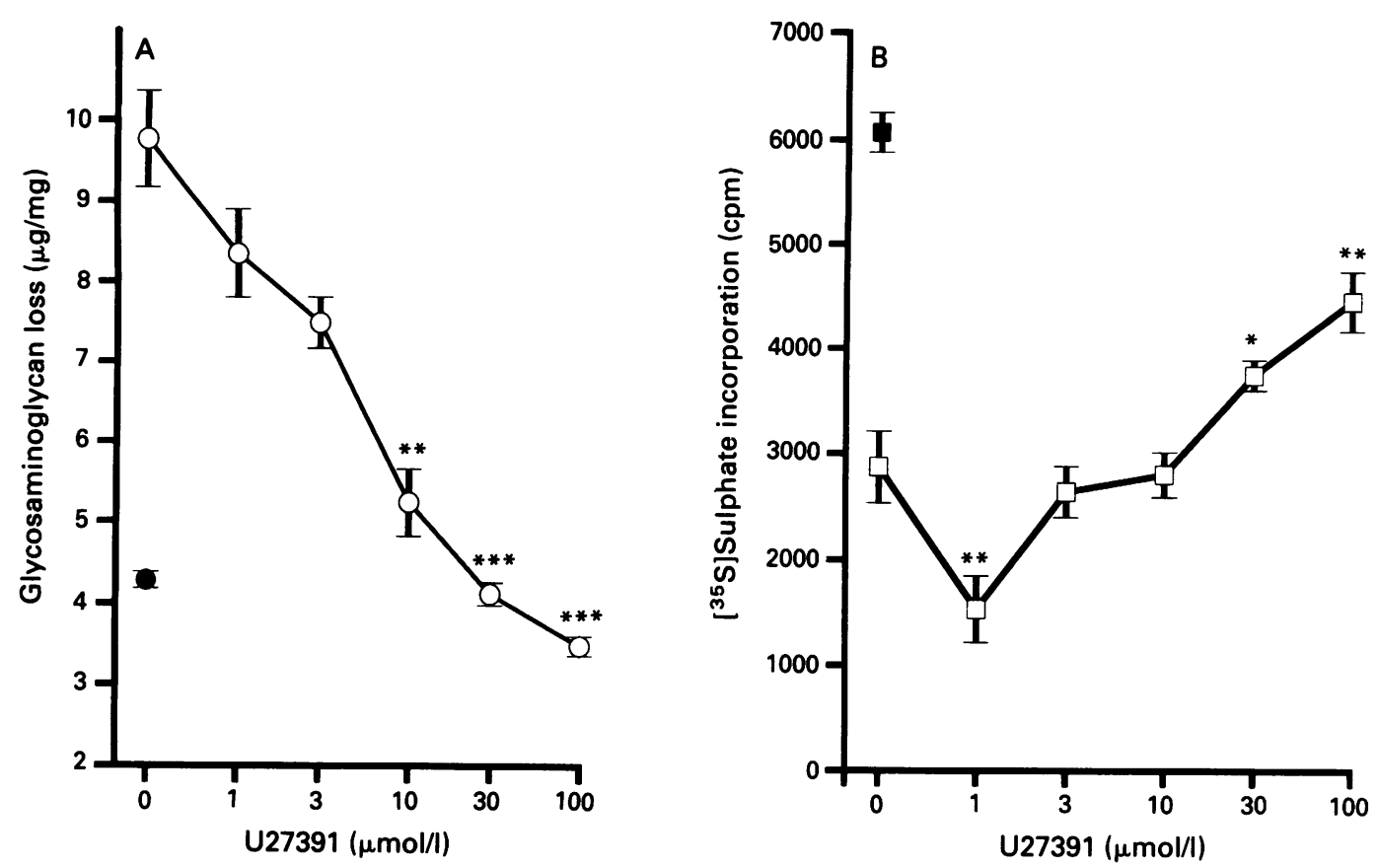

Figure 4 Reversal of recombinant human interleukin $1 \beta(\mathrm{rhIL}-1 \beta)(100 \mathrm{ng} / \mathrm{ml})$ induced $(A)$ glycosaminoglycan loss and (B) inhibition of $\left[^{35}\right.$ Ssulphate incorporation by rat femoral head cartilage in culture (mean $(S E M){ }^{*} p<0 \cdot 05 ; * * p<0 \cdot 01$; $\left.{ }_{* * *}<0.001 ; n=10\right)$ by U27391. Closed symbols indicate basal controls without rhIL-1P. Cartilages killed by freeze thawing contained $67 \cdot 7(8 \cdot 7) \mathrm{cpm}\left[{ }^{35}\right.$ Ssulphate.

U27391 in the presence of $10 \mathrm{ng} / \mathrm{ml}$ rhIL-1 $\beta$ and fig 5 shows that these explants lost significantly less glycosaminoglycan than those incubated with rhIL-1 $\beta$ alone. The loss of glycosaminoglycan content from 10 biopsy samples was reduced from $18 \cdot 6(2 \cdot 6) \%$ to $10.4(2.5) \quad(\mathrm{p}<0.01), 5 \cdot 6(4 \cdot 1) \quad(\mathrm{p}<0.01)$ and

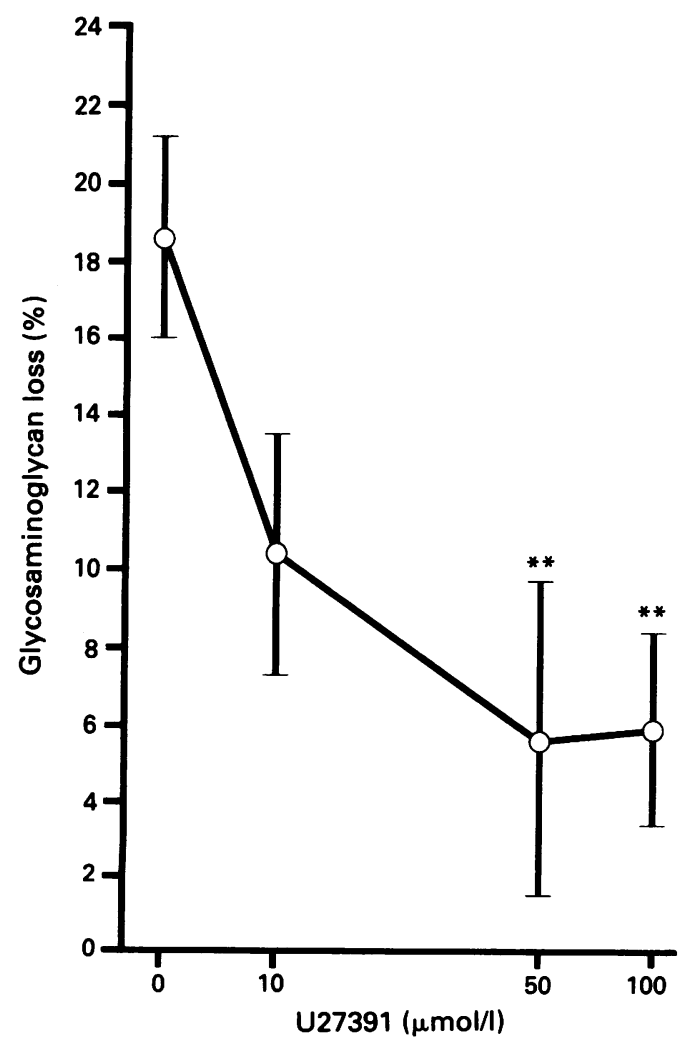

Figure 5 Example of the inhibition of recombinant human interleukin $18(10 \mathrm{ng} / \mathrm{ml})$ induced glycosaminoglycan loss from human femoral head cartilage by 10-100 $\mu \mathrm{M}$ U27391 (mean (SEM). ${ }^{* *} p<0.01 ; n=10$ samples).
$5.9(2.6) \%(\mathrm{p}<0.01)$ at 10,50 and $100 \mu \mathrm{mol} / 1$ U27391 respectively. Similar results were obtained with explants from another cartilage, responsive to rhIL-1 $\beta$ from a patient with osteoarthritis. The percentage loss of glycosaminoglycan compared with control biopsy samples incubated with rhIL-1 $\beta$ was $12 \cdot 6(3 \cdot 0)$, and $8 \cdot 9(4 \cdot 3), 12 \cdot 2(3 \cdot 1)$ and $4 \cdot 3(6 \cdot 6)$ for explants incubated with rhIL-1 $\beta$ in the presence of 10 , 50, and $100 \mu \mathrm{mol} / \mathrm{l} \mathrm{U} 27391$ respectively. The significance was affected by the variable glycosaminoglycan content between the biopsy samples, a characteristic of this disease.

\section{Discussion}

The results reported in this paper compare the response of rat and human femoral articular cartilage to rhIL-1 $\beta$ and its reduction by a metalloproteinase inhibitor. Although there is considerable evidence for the degradation of animal cartilage in response to IL-1, ${ }^{2-11}$ there is less evidence for human cartilage responding to IL-1 in a similar fashion. For example, Campbell $e t$ al claim to be the first to show glycosaminoglycan release from human cartilage explants, though the number of times this result was obtained is unclear. ${ }^{35}$ Similarly Shinmei $e t$ $a l^{16}$ reported briefly that IL-1 stimulated glycosaminoglycan loss from human cartilage slices as judged by the reduction in staining with toluidine blue. The source and purity of the IL-1 used was not given, however. Although this paucity of information could be due to differences in the incubation requirements of human cartilage described here and elsewhere, ${ }^{36}$ it has also become apparent, as is confirmed here, that there may be two populations of human cartilage which differ in their ability to respond to IL-1, ${ }^{17}$ with only about a third being responsive to degradation. ${ }^{17}{ }^{37}$ Probably for this 
reason investigations into the actions of IL-1 on human cartilage have been impeded.

We have tested several samples of human femoral head cartilage for their reactivity to rhIL-1 $\beta$ and investigated the inhibition of metalloproteinase using the synthetic inhibitor U27391. By necessity, direct comparisons with rat femoral head cartilage using identical incubation conditions cannot be made, as under the optimum conditions and short five day time course described here for rat femoral head cartilage, human femoral head cartilage does not respond to rhIL-1 $\beta$ with a reduction in glycosaminoglycan content. ${ }^{36}$ Conversely, we have found that rat femoral head cartilage incubated under conditions favourable for human femoral head cartilage does not respond optimally (data not shown). Differences in the sampling of the tissues have also necessitated the use of different methods for expressing glycosaminoglycan loss, as the glycosaminoglycan content of human femoral head cartilage varies according to the site of biopsy, and thus comparison must be made with paired biopsy samples taken from the same area. This technique cannot be applied to rat femoral head cartilage as the division of the femoral head cartilage into two results in substantial and sustained glycosaminoglycan loss. The glycosaminoglycan release into the supernatants for human cartilage explants is $<10 \mu \mathrm{g} / \mathrm{ml}$, which is less than the limit of detection of the glycosaminoglycan assay. The most likely explanation for this finding is that as the glycosaminoglycan content of the explants averages about $150 \mu \mathrm{g}$ (4.5 mg at $33 \mu \mathrm{g}$ glycosaminoglycan $/ \mathrm{mg}$ mass) and only $20 \%$ was lost, then at most only $30 \mu \mathrm{g}$ will be released over the 14 day incubation period. As the medium was collected every two days, it would contain less than $5 \mu \mathrm{g} / \mathrm{ml}$ on average.

The main finding reported here is that rat femoral head cartilage responds to IL-1 with a dose dependent loss of proteoglycan into the incubation medium coupled with a reduction in $\left[{ }^{35} \mathrm{~S}\right]$ sulphate uptake and thus proteoglycan synthesis. Likewise the human femoral head cartilage samples chosen for this study responded with a reduction in proteoglycan content. Rat femoral head cartilage in general appears to be less sensitive to rhIL-1 $\beta$ than human femoral head cartilage, probably as a result of the species difference, which necessitated the use of $100 \mathrm{ng} / \mathrm{ml} \mathrm{rhIL}-1 \beta$ as opposed to $10 \mathrm{ng} / \mathrm{ml}$ in human femoral head cartilage when assessing the effect of U27391. In the two instances, incubation with $\mathrm{U} 27391$ resulted in the inhibition of proteoglycan loss. Previously, attempts to inhibit IL-1 induced proteoglycan loss from living cartilage by various biochemical inhibitors of metalloproteinases have met with little success, ${ }^{30}{ }^{38}$ with the exception of three examples of the hydroxamic acid series, U24522 and $\mathrm{U}^{24278^{\circ}}$ and Ro31-4724. ${ }^{39}$ Although it could be argued that these agents are acting through non-specific actions on cartilage, as found with chloroquine, 1,10-phenanthroline, and APMA, for example, ${ }^{11}$ they do not inhibit cartilage viability at active concentrations. ${ }^{9}$ We also observed no significant changes in sulphate incorporation at concentrations between 3 and $100 \mu \mathrm{mol} / 1$, but with an atypical reduction in sulphate incorporation at $1 \mu \mathrm{mol} / 1 \mathrm{U} 27391$. This remains unexplained; however, this effect did occur in more than one experiment and was not reflected in changes in glycosaminoglycan loss. Typically, we have found that significant and dose related changes in either protein synthesis or sulphate incorporation are required before a reduction in rhIL-1 $\beta$ stimulated glycosaminoglycan loss is seen, ${ }^{11} 30$ which is not the case here. More importantly the opposite occurred, and the rhIL-1 $\beta$ induced reduction in $\left[{ }^{35} S\right]$ sulphate incorporation by rat femoral head cartilage was substantially attenuated by treatment with U27391. This could indicate, but does not prove, that the inhibition of metalloproteinase activity may not only prevent proteoglycan degradation induced by IL-1, but also allows a recovery of proteoglycan synthesis or its retention within the cartilage, in a manner true to the concept of 'chondroprotection'.

Although showing that the inhibition of cartilage degradation by reducing metalloproteinase activity in human cartilage is a promising approach to the problem of cartilage degradation in disease, the data presented here conversely illustrate the importance of metalloproteinases in rhIL-1 $\beta$ induced proteoglycan loss. U27391 is active against the proteoglycanase and collagenase released by IL-1 stimulated chondrocytes, but is tenfold more active against the former $\left(\mathrm{IC}_{50} 4 \cdot 2 \times 10^{-8}\right.$ and $4 \cdot 1 \times 10^{-7} \mathrm{~mol} / 1$ respectively). ${ }^{32}$ Other as yet uncharacterised mechanisms of cartilage degradation are being revealed, however. Studies of the proteoglycan fragments released from stimulated cartilage in vitro have identified the initial sites of cleavage to be between the $G 1$ and $G 2$ globular domains of the proteoglycan core protein. ${ }^{40} 41$ Interestingly, a major site of cleavage on the core protein uncharacteristic of that required by stromelysin has been identified. ${ }^{42-44}$ The involvement of cysteinyl proteases has also been shown in the degradation of discs of bovine nasal septum with the use of the lipophilic cysteinyl protease inhibitor EP475. ${ }^{45}$ Other inhibitors without lipophilicity were found to be inactive, indicating either intracellular compartmentalisation of the enzymes or their release into other loci requiring membrane penetration. It is unknown if these mechanisms are important in the initial processes for the cleavage of the proteoglycan core protein as fragments characteristic of cysteinyl proteinase activity are not found. Despite these possibilities, metalloproteinase inhibition with U27391 remains effective, and could reflect the relatively uncharacterised nature of the enzymes against which it was developed. ${ }^{21} 2246$ Although U27391 reduced rhIL-1 $\beta$ stimulated and unstimulated proteoglycan loss to less than basal levels to a similar degree, it remains to be shown at which position the remaining core proteins are cleaved to determine the residual mechanisms under these conditions.

In the absence of effective protection against cartilage erosion in RA and OA, it is promising to note that an agent developed as an inhibitor 
of rabbit metalloproteinase in in vitro animal systems is effective using human cartilage. We conclude that the inhibition of metalloproteinase activity is an effective method of reducing rhIL-1 $\beta$ induced proteoglycan loss from rat and, more importantly, human articular cartilage. There is an indication that this inhibition may also result in more efficient proteoglycan retention or synthesis by cartilage under conditions of synthesis inhibition and requires further investigation.

We thank Stuart Pharmaceuticals (ICI Americas) for the kind donation of U27391.

1 Fell $H$, Jubb $R$. The effect of synovial tissue on the breakdown of articular cartilage in organ culture. Arthritis Rheum 1977; 20: 1359-71.

2 Saklatvala J, Pilsworth L, Sarsfeld S, Gavrolovic J, Heath J Pig catabolin is a form of interleukin-1. Biochem $\mathcal{F} 1984$; 224: $461-6$.

3 Wood D D, Ihrie E J, Hammerman D. Release of interleukin-1 from human synovial tissue in vitro. Arthritis Rheum 1985; 28: 853-62.

4 Duff G W, Dickens E, Wood N, et al. Immunoassay, bioassay and in situ hybridisation of monokines in human arthritis. In: Powanda M, Oppenheim J J, Kluger M, Dinarello C A, eds. Progress in leucocyte biology. Vol. 8 . New York: Liss, 1988: 387-92.

5 Fontana A, Hengartner J, Weber E, Fehr K, Grob J, Cohen G. Interleukin-1 activity in synovial fluid of patients with rheumatoid arthritis. Arthritis Rheum 1982; 25: 49-53.

6 Wood D D, Ihrie E J, Dinarello C A, Cohen P L. Isolation of an interleukin-1-like factor from joint effusions. Arthritis Rheum 1983; 26: 975-83.

7 Smith J B, Bochier M H, Sherbin-Allen L, Borofsky M, Abruzzo J L. Occurrence of interleukin-1 in human synovial fluid: detection by RIA, bioassay, and presence of bioassay-inhibiting factors. Rheumatol Int 1989; 9: 53-8.

8 Tyler J A, Saklatvala J. Pig interleukin-1 (catabolin) induces resorption of cartilage proteoglycan and prevents synthesis of proteoglycan and collagen. $\mathrm{Br} \mathcal{F}$ Rheumatol $1985 ; 24(\mathrm{~S} 1)$ : $150-5$.

9 Caputo C B, Sygowski L A, Wolanin D J, et al. Effect of synthetic metalloprotease inhibitors on cartilage autolysis in vitro. I Pharmacol Exp Ther 1987; 240: 460-5.

10 van den Berg W B, van de Loo F A J, Zwart W A, Otterness I G. Effects of murine recombinant interleukin-1 on intact homologous articular cartilage: a quantitative and autoradiographic study. Ann Rheum Dis 1988; 47: 855-63.

11 Clay K, Seed M P, Clements-Jewery S. Studies on interleukin-1 $\beta$ induced glycosaminoglycan release from rat 41: $503-4$.

12 Pettipher E R, Higgs G A, Henderson B. Interleukin-1 induces leucocyte infiltration and cartilage proteoglycan degradation in the synovial joint. Proc Natl Acad Sci 1986 83: 8749-53.

13 van de Loo F A J, van Beuningen $H M$, van Lent $P$, van den Berg $W$ B. Direct effect of murine rIL-1 on cartilage metabolism in vitro. Agents Actions 1989; 26: 153-5.

14 Chandrasekhar S, Harvey A K, Hrubey P S, Bendele A M Arthritis induced by interleukin-1 is dependent on the site
and frequency of intraarticular injection. Clin Immunol and frequency of intraarticular inje

15 Campbell I K, Roughly P J, Mort J S. The action of human articular-cartilage metalloproteinase on proteoglycan and link protein. Biochem $\mathcal{f}$ 1986; 237: 117-22.

16 Shinmei M, Kikuchi T, Masuda K, Shimomura Y. Effects of interleukin- 1 and antiinflammatory drugs on the degradation of human articular cartilage. Drugs 1988; 35(S1); $33-41$.

17 Ismaiel S, Atkins R M, Pearse M F, Dieppe P A, Elson C J. Susceptibility of normal and arthritic human articular Susceptibility of normal and arthritic human articular
cartilage to degradative stimuli. $\operatorname{Br} \mathcal{F}$ R heumatol 1992; 31: cartilage

18 Ratcliffe A, Tyler J A, Hardingham T E. Articular cartilage cultured with interleukin 1 . Biochem $\mathcal{F}$ 1986; 238: 571-80.

19 Deshmukh-Phadke K, Lawrence M, Nanda S. Synthesis of collagenase and neutral proteases by articular chondrocytes: stimulation by a macrophage-derived factor. Biochem Biophys Res Commun 1978; 85: 490-6.

20 Gowen M, Wood D D, Ihrie E J, Meats J E, Russel R G G. Stimulation by human interleukin-1 of cartilage breakdown and production of collagenase and proteoglycanase by human chondrocytes but not by human osteoblasts in vitro. Biochim Biophys Acta 1984; 797: 186-93.

21 Pasternak R D, Hubbs S J, Caccese R G, Marks R L, Conalty J M, DiPasquale G. Interleukin-1 stimulates the secretion of proteoglycan- and collagen-degrading proteases by rabbit articular chondrocytes. Clin Immunol Immunopathol 1986; 41: $351-67$.
22 Dipasquale G, Caccese R, Pasternak R, Perry K, Conalty J, Hubby S. Partial characterisation of collagen and proteoglycan-degrading enzymes from rabbit and human osteo-
arthritic chondrocytes stimulated with human IL-1. Adv arthritic chondrocytes stim

23 Schnyder J, Payne T, Dinarello C A. Human monocyte or recombinant interleukin 1's are specific for the secretion of a metalloproteinase from chondrocytes. I Immunol 1987 138: 496-503.

24 Nguyen Q, Murphy G, Roughley P J, Mort J S. Degradation of proteoglycan aggregate by a cartilage metalloproteinase. Evidence for the involvement of stromelysin in the generation of link protein heterogeneity in situ. Biochem $\mathcal{F}$ 1989; 259: 61-7.

25 Campbell I K, Golds E E, Mort J S, Roughley P J. Human articular cartilage secretes characteristic metal-dependent articular cartilage secretes characteristic metal-dependent proteinases upon stimulation

26 Salposky A I, Malemud C J, Norby D P. Metalloproteases of human articular cartilage that digest cartilage at neutral and acid pH. F Clin Invest 1976; 58: 1030-41.

27 Salposky A I, Malemud C J, Norby D P, Moskowitz R W, Matsuka K, Howell D S. Neutral proteinases from articular chondrocytes in culture. Biochim Biophys Acta 1981; 658: $138-47$.

28 Hembury R M, Knight C G, Dingle J T, Barret A J. Evidence that cathepsin $D$ is not responsible for the resorption of cartilage matrix in culture. Biochim Biophys Acta 1982; 714: 307-12.

29 Smith R J, Rohloff N A, Sam L M, Justen J M, Deibel M R Cornette J C. Recombinant human interleukin-l $\alpha$ and

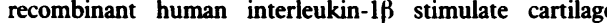
matrix degradation and inhibit glycosaminoglycan synthesis. Inflammation 1989; 13: 367-82.

30 Seed M P, Thomson T A, Gardner C R. Investigation of the role of metalloproteinases in recombinant human interleukin- $1 \beta$ induced degradation of rat femoral head cartilage. Drugs Exp Clin Res 1991; 17: 355-61.

31 Shaw A, Roberts R A, Wolanin D J. Small substrates and inhibitors of the metalloproteoglycanase of rabbit articular chondrocytes. Adv Inflam Res 1988; 12: 67-79.

32 Dipasquale G. An anti-osteoarthritic drug developmen program: an overview. Adv Inflam Res 1988; 12: 55-65.

33 Farndale R W, Buttle D J, Barret A J. Improved quantitation and discrimination of sulphated glycosaminoglycans by use of dimethylmethylene blue. Biochim Biophys Acta 1986, 883: 173-7.

34 Jubb $\mathbf{R}$ W, Fell $H$ B. The effect of synovial tissue on the synthesis of proteoglycan by the articular cartilage of young synthesis of proteoglycan by the articular car
pigs. Arthritis Rheum 1980; 23: 545-55.

35 Campbell J K Piccoli D S, Butler D M, Singleton D K Hamilton J A. Recombinant human interleukin-1 stimulates human articular cartilage to undergo resorption and human chondrocytes to produce both tissue- and urokinase-typ plasminogen activator. Biochim Biophys Acta 1988; 967: 183-94.

36 Ismaiel S, Hollander A P, Atkins $\mathbf{R} M$, Elson $C \mathrm{~J}$. Differential responses of human and rat cartilage to degrading stimuli in vitro. $\mathcal{f}$ Pharm Pharmacol 1991; 43: 207-9.

37 Hickery M S, Bayliss M T, Hardingham T E. The effect of interleukin-1 and tumour necrosis factor-alpha on the turnover of proteoglycans in human articular cartilage Biochem Soc Trans 1990; 18: 953-4.

38 Saklatvala J, Sarsfeld S J. How do interleukin-1 and tumou necrosis factor induce degradation of proteoglycan in cartilage? In: Glauert A M, ed. The control of tissue damage. Amsterdam: Elsevier, 1988: 97-108.

39 Nixon J S, Bottomley K M K, Broadhurst M J, et al. Poten collagenase inhibitors prevent IL-1-induced cartilage collagenase inhibitors prevent IL-1-induced cartilage

40 Sandy J S, Boynton R E, Flannery C R. Analysis of the catabolism of aggrecan in cartilage explants by quantitation of peptides from the three globular domains. $\mathcal{F} \mathrm{Biol}$ Chem 1991; 13: 8198-205.

41 Murphy G, Hembury R M, Hughes C E, Fosang A J Hardingham T E. Role and regulation of metalloproteinases in connective tissue turnover. Biochem Soc Trans 1990; 18: $812-5$

42 Sandy J D, Neame P J, Boynton R E, Flannery C R. Catabolism of aggrecan in cartilage explants. 7 Biol Chem 1991; 14: 8683-5.

43 Fosang A J, Neame P J, Hardingham T E, Murphy G, Hamilton J A. Cleavage of cartilage proteoglycan between G1 and G2 domains by stromelysins. F Biol Chem 1991; 266: 15579-82.

44 Hughes C, Murphy G, Hardingham T E. Metalloproteinase digestion of cartilage proteoglycan-pattern of cleavage by stromelysin and susceptibility to collagenase. Biochem 1991; 279: 733-9.

45 Buttle D J, Saklatvala J, Tamai M, Barrat A J. Inhibition of interleukin 1-stimulated cartilage proteoglycan degradation by a lipophilic inactivator of cysteine endopeptidases. by a lipophilic inactivator
Biochem $\mathcal{F} 1992 ; 281$ : 175-7.

46 Pasternak R D, Hubbs S I, Caccese R G, Marks R L, Conaty J M, Dipasquale G. Interleukin-1 induces chondrocyte protease production. The development of collagenase inhibitors. Agents Actions 1987; 21: 328-40. 